\title{
A VIOLAÇÃO AOS DIREITOS FUNDAMENTAIS DO ADOTANDO QUANDO DO ROMPIMENTO DO VÍNCULO EM VIRTUDE DA DESISTÊNCIA DOS ADOTANTES DURANTE O ESTÁGIO DE CONVIVÊNCIA
}

\author{
THE VIOLATION OF THE FUNDAMENTAL RIGHTS OF THE ADOPTING WHEN \\ THE BREAKING OF THE LINK IN VIRTUE OF THE WITHDRAWAL OF THE \\ ADOPTERS DURING THE STAGE OF CONVIVENCE
}

\author{
Denner Guedes Neiva \\ Bacharel em Direito, Brasil, \\ e-mail: dennerguedess@hotmail.com \\ Márcio Júnio Batista Pereira \\ Especialista em Direito do Trabalho, \\ Fundação Presidente Antônio Carlos, \\ e-mail: marciojuniotoadv@hotmail.com
}

Recebido: 01/05/2020 - Aceito: 20/05/2020

\section{Resumo}

No ordenamento jurídico brasileiro, muitas vezes o processo de adoção não é concretizado devido à possibilidade de desistência por parte dos adotantes durante o estágio de convivência. Em razão disso, a proposta do presente artigo científico é investigar, por meio de revisão bibliográfica e jurisprudencial, sobre a violação a direitos fundamentais do adotando quando do rompimento do vínculo com os pretensos adotantes durante o estágio de convivência. Desse modo, em virtude dessa ruptura de vínculos e violação à dignidade da pessoa humana, muitos tribunais do Brasil, em julgamento de casos concretos, vêm impondo aos adotantes o dever de indenizar o adotando pelo dano moral sofrido, que muito embora não seja a solução do problema, busca dar um suporte e amenizar o abuso de direito sofrido pelo infante.

Palavras-chave: Adoção; Direitos fundamentais; Estágio de convivência.

\section{Abstract}

In the brazilian legal system, often the adoption process is not materialized due to the possibility of abandonment by the adopters during the foster care stage. Thence, the 
proposal of this cientific article is to investigate the violation of the adoptee's fundamental rights when there's a disruption of the adoption process during the foster care stage. For this reason, the purpose of this scientific article is to investigate, through bibliographic and jurisprudential review, the violation of the fundamental rights of the adoptee when the bond with the alleged adopters is broken during the coexistence stage. Thus, due to this rupture of ties and violation of the dignity of the human person, many courts in Brazil, in judging concrete cases, have imposed on the adopters the obligation to compensate the adopting party for the moral damage suffered, although, is not the problem's solution, seeks to support and mitigate the abuse of rights suffered by the adoptee.

Keywords: Adotion; Fundamental Rights; Foster Care.

\section{INTRODUÇÃO}

A adoção é precedida por uma sucessão de etapas antes de atingir seu caráter definitivo, dentre elas o estágio de convivência, período em que muitas vezes surgem impasses que resultam na desistência da medida por parte dos pretensos adotantes.

Dessa forma, ao passo em que o legislador conferiu ao adotante a faculdade de desistir da adoção até o trânsito em julgado da decisão, propõe-se no artigo científico analisar, de forma não exaustiva, a violação a direitos fundamentais dos adotandos, quando do rompimento de vínculo após o estágio de convivência, partindo da seguinte indagação: há violação aos direitos fundamentais do adotando quando do rompimento do vínculo com os pretensos adotantes em virtude da desistência desses durante o estágio de convivência?

Os direitos fundamentais outorgados pela Constituição Federal de 1988 são imprescindíveis à vida de qualquer cidadão, e estão intimamente ligados ao fundamento da dignidade da pessoa humana. Dessa maneira, surge a relevância do tema abordado no presente estudo, pois, a partir do momento em que os adotantes desistem da adoção, e consequentemente rompem o vínculo com o adotando, este, por sua vez, não gozará dos direitos fundamentais em sua totalidade, havendo uma limitação, por exemplo, em relação ao direito da convivência familiar e comunitária, que necessita de uma família para o seu exercício.

Sobre esse aspecto, tendo em vista os recorrentes casos de devolução de crianças e adolescentes às instituições de acolhimento, os tribunais de justiça do 
Brasil, ao julgarem casos concretos, vêm impondo aos adotantes o dever de indenizar o adotando pelo dano moral sofrido.

Por fim, a proposta metodológica utilizada se deu por meio de análise bibliográfica, jurisprudencial e artigos científicos correlacionados com a temática abordada.

\title{
2 A DOUTRINA DA PROTEÇÃO INTEGRAL
}

Os direitos da criança e do adolescente foram conquistados durante um longo processo, principalmente após o fim da Segunda Guerra Mundial.

Em 1959, com a adoção da Declaração Universal dos Direitos da Criança e dos Adolescentes pela Assembleia Geral das Nações Unidas, originou-se a denominada Doutrina da Proteção Integral, que somente foi inserida no nosso ordenamento pátrio com o advento da Constituição Federal de 1988.

Mais tarde, a instituição da doutrina da proteção integral consolidou-se com a Convenção Internacional dos Direitos da Criança de 1989, "reunindo todas as normas internacionais referentes à infância, estabelecendo determinações que serviram como diretrizes a formulação do Estatuto da Criança e do Adolescente no Brasil."1

A Doutrina da Proteção Integral foi precedida pela Doutrina da Situação Irregular, consubstanciada no Código de Menores, Lei no 6.697/79, que dava um tratamento genérico ao menor, ou seja, a criança e o adolescente só eram percebidos quando estavam em uma situação irregular.

Nesta senda, Veronese e Silveira (2011, p. 217) discorrem:

\begin{abstract}
A doutrina da situação irregular encaixava crianças e adolescentes em um quadro de uma suposta patologia social: 0 carente, 0 delinquente, 0 abandonado, entre outras categorias e, assim, eximia o Estado da responsabilidade da efetiva aplicação das medidas contidas em seu bojo, já que os grandes responsáveis pela "delinquência" e pela "situação irregular"
\end{abstract}

\footnotetext{
${ }^{1}$ Ver. CLARINDA, Katherine Scherer. A doutrina da proteção integral e os direitos fundamentais como ensejadores do reconhecimento da adoção por companheiros homoafetivos. Publicado em 09/2017. Disponível em: <https://jus.com.br/artigos/60561/a-doutrina-da-protecao-integral-e-os-direitos-fundamentaiscomo-ensejadores-do-reconhecimento-da-adocao-por-companheiros-homoafetivos > Acesso em: 22 de abril de 2019.
} 
eram os próprios menores, vistos como meros objetos das políticas de controle social do Estado e não como sujeitos de direitos.

Com a promulgação da Constituição Federal de 1988, a doutrina da proteção integral está estampada no art. 227 da Carta Magna. Assim, dispõe em seu caput:

É dever da família, da sociedade e do Estado assegurar à criança, ao adolescente e ao jovem, com absoluta prioridade, o direito à vida, à saúde, à alimentação, à educação, ao lazer, à profissionalização, à cultura, à dignidade, ao respeito, à liberdade e à convivência familiar e comunitária, além de colocá-los a salvo de toda forma de negligência, discriminação, exploração, violência, crueldade e opressão. (BRASIL, 1988). ${ }^{2}$

Dessa forma, a partir do momento em que tal doutrina fora inserida no ordenamento jurídico brasileiro, a criança e o adolescente passaram a ser reconhecidos como sujeitos de direito, levando-se em consideração a sua condição peculiar de indivíduos em desenvolvimento.

Para tanto, nas palavras de Veronese (2006, p.53):

É preciso compreender que o termo proteção integral não se refere somente à prioridade e à relevância que os interesses das crianças e dos adolescentes devem ter, mas também pela razão de que o Estatuto se destina a todos os menores de 18 anos (e excepcionalmente dos 18 aos 21 anos, como dispõe o parágrafo único do artigo $2^{\circ}$ ) em qualquer situação, sejam eles negros, brancos, ricos, pobres, saudáveis ou portadores de deficiência.

Em linhas gerais, a doutrina da proteção integral normatizada pelo Estatuto da Criança e do Adolescente veio romper de vez os vínculos com o já revogado Código de Menores, estabelecendo normas, regras e princípios que garantam, prioritariamente, a aplicação de todos os direitos fundamentais previstos na

\footnotetext{
${ }^{2}$ Ver. BRASIL, Constituição (1988). Constituição Federal da República Federativa do Brasil. Brasília, 5 de outubro de 1988. Disponível em: http://www.planalto.gov.br/ ccivil_03/Constituicao/Constitui\%C3\%A7ao.htm. Acesso em: 22 de abr. de 2019.
} 
Constituição Federal, assim como àqueles decorrentes do estatuto supramencionado ao público infantojuvenil.

Visando dar maior aplicabilidade à proteção integral, o princípio do melhor interesse da criança e do adolescente reforça o dever da família, juntamente com a sociedade e o Estado, de assegurarem à criança e ao adolescente, com absoluta prioridade, todos os direitos inerentes à pessoa humana. Logo, a família torna-se um instrumento necessário para conduzir o bom desenvolvimento da personalidade de seus membros.

Nesse trilhar, Lôbo (2011, p. 75 ):

O princípio parte da concepção de ser a criança e o adolescente como sujeitos de direitos, como pessoas em condição peculiar de desenvolvimento, e não como mero objeto de intervenção jurídica e social quando em situação irregular, como ocorria na legislação anterior sobre os "menores". Nele se reconhece o valor intrínseco e prospectivo das futuras gerações, como exigência ética de realização de vida digna para todos.

Assim sendo, deve-se levar em consideração que o princípio do melhor interesse da criança e do adolescente deve ser interpretado como um fundamento primário de todas as ações direcionadas à população infantojuvenil, uma vez que todas as decisões que envolvam a referida população devam ser tomadas com cautela e com o que há de melhor e mais adequado para satisfazer os seus interesses e suas necessidades.

\section{DA COLOCAÇÃO EM FAMÍLIA SUBSTITUTA}

Família substituta pode ser conceituada como aquela que recebe a criança ou o adolescente na ausência ou impossibilidade da família natural.

A colocação em família substituta está regida no artigo 28 e seguintes do Estatuto da Criança e do Adolescente, em consonância com o § 3ํ do artigo 19 desse mesmo Estatuto.

A inserção de criança e adolescente em família substituta tem caráter excepcional, conforme elenca o artigo 19, § $3^{\circ}$ do mesmo diploma legal (1990), in verbis: 
Art. 19. É direito da criança e do adolescente ser criado e educado no seio de sua família e, excepcionalmente, em família substituta, assegurada a convivência familiar e comunitária, em ambiente que garanta seu desenvolvimento integral.

$(\ldots)$

§ 30 A manutenção ou a reintegração de criança ou adolescente à sua família terá preferência em relação a qualquer outra providência, caso em que será esta incluída em serviços e programas de proteção, apoio e promoção, nos termos do $\S 10$ do art. 23, dos incisos I e IV do caput do art. 101 e dos incisos I a IV do caput do art. 129 desta Lei. (BRASIL, 1990). ${ }^{3}$

Outrossim, a criança ou adolescente será inserida na família substituta somente no último caso, após esgotados todos os meios de reinserção na família natural e extensa. "Ressalta-se ainda que a adoção não é a única modalidade de colocação em família substituta, havendo outras formas, como a tutela e a guarda, estabelecidas no artigo 28 da Lei n. 8.069/1990" (FELIPE, 2016).

Por fim, destaca-se que depois de realizadas todas as etapas da adoção, esta atinge o seu caráter definitivo, de maneira que o infante passa a integrar outra família, tornando-se filho dos adotantes, desvinculando-se por completo de sua família de origem.

\section{O INSTITUTO DA ADOÇÃO NO ESTATUTO DA CRIANÇA E DO ADOLESCENTE}

O instituto jurídico da adoção é tratado pelo Estatuto da Criança e do Adolescente nos artigos 39 a 52, com alterações trazidas pela Lei № 12.010/2009, com o intuito de reforçar a garantia do direito à convivência familiar.

Ao longo da história, no Direito Civil brasileiro, o conceito de família sofreu várias modificações e reformulações. Antigamente tal conceito era exclusivamente limitado às relações constituídas por meio do casamento e aos vínculos biológicos. Entretanto, "hoje cada vez mais se prioriza a concepção de família como espaço de

\footnotetext{
${ }^{3}$ Ver. BRASIL. Lei n. 8.069, de 13 de julho de 1990. Dispõe sobre o Estatuto da Criança e do Adolescente. Disponível em: http://www.planalto.gov.br/ccivil_03/LEIS/L8069.htm. Acesso em: 22 de abr. 2019.
} 
vínculos afetivos, de espaço para a formação de valores, com ênfase à liberdade, ao respeito, à dignidade de cada elemento que a compõe." (VERONESE, 2004).

É sob esse prisma que o instituto da adoção ganha destaque, sendo $O$ ato jurídico no qual possibilita que a criança e o adolescente possam gozar do estado de filho, independentemente do vínculo biológico, pautando-se, assim, no afeto e cumprindo o direito à convivência familiar que advém da Constituição Federal.

Sendo assim, a adoção é um ato jurídico bilateral de filiação, calcado no afeto e na afinidade, que permite a aceitação de alguém como filho.

Nesse sentido, enfatiza Diniz (2013, p. 522):

A adoção vem a ser o ato jurídico solene pelo qual, observados os requisitos legais, alguém estabelece, independentemente de qualquer relação de parentesco consanguíneo ou afim, um vínculo fictício de filiação, trazendo para sua família, na condição de filho, pessoa que, geralmente lhe é estranha.

Sobre a temática, preleciona Venosa (2013, p. 288):

\begin{abstract}
O Estatuto da Criança e do Adolescente, especificamente quanto à adoção, descreve que a criança ou adolescente tem direito fundamental de ser criado e educado no seio de uma família, natural ou substituta (art. $1^{\circ}$ ). $O$ estatuto considera a criança e o adolescente sujeitos de direito, ao contrário do revogado Código de Menores, que os tratava como objeto de relação jurídica, deixando mais claro e espectro de direitos subjetivos.
\end{abstract}

O Estatuto da Criança e do Adolescente, em seu art. $2^{\circ}$, para os seus devidos efeitos, considera como criança a pessoa que possui até doze anos de idade incompletos, e o adolescente aquela entre doze e dezoitos anos. "Suprimiu-se o termo menor, que teria recebido conotação depreciativa na referência do Código de Menores". (VENOSA, 2013).

Não se pode olvidar, que ao inserir o Estatuto da Criança e do Adolescente no ordenamento jurídico brasileiro, o legislador, eminentemente, visa dar prioridade àquelas pessoas com idade inferior a dezoito anos. Entretanto, como bem elenca 0 
parágrafo único do dispositivo legal supramencionado, é aplicado excepcionalmente às pessoas com idade entre dezoito e vinte e um anos.

Nesses moldes, para se compreender melhor o assunto em estudo, convém destacar a redação trazida pelo art. 40 do ECA, in verbis: "o adotando deve contar com, no máximo, dezoito anos à data do pedido, salvo se já estiver sob a guarda ou tutela dos adotantes".

Diante dessa análise, o adotando quando atingida a sua maioridade e já esteja sob a guarda ou tutela dos pretendentes à adoção, serão aplicadas as normas atinentes ao Estatuto da Criança e do Adolescente, inserindo-se na competência da Vara da Infância e Juventude o seu processamento e julgamento.

Além de ser personalíssima, a adoção é uma medida excepcional, uma vez que se prima pela manutenção da criança ou adolescente no seio de sua família natural ou extensa. Ademais dessas características positivadas no art. 39, do ECA, a adoção possui caráter irrevogável, ou seja, após o trânsito em julgado da sentença que a deferiu, a medida torna-se definitiva, não admitindo renúncia ou desistência por parte dos adotantes.

Seguindo essa premissa, Venosa (2013, p. 289) dispõe mais uma vez:

\begin{abstract}
Ao lado da família natural, coloca-se a entidade denominada família substituta. A alternativa da família substituta para o menor deve surgir somente quando todas as possibilidades de manutenção do infante em sua família natural se esvaem. Desse modo, a colocação do menor em família substituta é medida excepcional de proteção destinada a amparar as crianças e adolescentes cujos direitos fundamentais se encontram suprimidos ou ameaçados. Nessa situação se inserem os menores em estado de abandono.
\end{abstract}

Importante ainda consignar que a Lei Nacional de Adoção veio para agilizar e desburocratizar o processo de adoção, facilitando o acesso de quem quer adotar uma criança, e consequentemente reduzir o número de crianças sem famílias.

Dessa forma, a pessoa ou casal que estão imbuídos pelo desejo de adotar devem preencher os requisitos legais que a adoção exige, conforme o Estatuto da Criança e do Adolescente, em seu art. 42: 
42. Podem adotar os maiores de 18 (dezoito) anos, independentemente do estado civil.

$\S 1$ 1Não podem adotar os ascendentes e os irmãos do adotando.

$\S 2^{\circ}$ Para adoção conjunta, é indispensável que os adotantes sejam casados civilmente ou mantenham união estável, comprovada a estabilidade da família.

$\S 3^{\circ} \mathrm{O}$ adotante há de ser, pelo menos, dezesseis anos mais velho do que o adotando.

$\S 4^{\circ}$ Os divorciados, os judicialmente separados e os ex-companheiros podem adotar conjuntamente, contanto que acordem sobre a guarda e o regime de visitas e desde que o estágio de convivência tenha sido iniciado na constância do período de convivência e que seja comprovada a existência de vínculos de afinidade e afetividade com aquele não detentor da guarda, que justifiquem a excepcionalidade da concessão.

$\S 5^{\circ}$ Nos casos do $\S 40$ deste artigo, desde que demonstrado efetivo benefício ao adotando, será assegurada a guarda compartilhada.

§ 6ำ A adoção poderá ser deferida ao adotante que, após inequívoca manifestação de vontade, vier a falecer no curso do procedimento, antes de prolatada a sentença. . (BRASIL, 1990). ${ }^{4}$

Conforme se vê pela redação do art. 42 , destaca-se, ainda, que o art. $50, \S 5^{\circ}$ do referido estatuto prescreve:

Art. 50. A autoridade judiciária manterá, em cada comarca ou foro regional, um registro de crianças e adolescentes em condições de serem adotados e outro de pessoas interessadas na adoção.

(...)

§ 50 Serão criados e implementados cadastros estaduais e nacional de crianças e adolescentes em condições de serem adotados e de pessoas ou casais habilitados à adoção. (BRASIL, 1990). ${ }^{5}$

Em consequência disso, antes de haver habilitação para o processo de adoção deve-se primeiramente preencher os requisitos trazidos no art. 42 do Estatuto da

\footnotetext{
${ }^{4}$ Ver. BRASIL. Lei n. 8.069, de 13 de julho de 1990. Dispõe sobre o Estatuto da Criança e do Adolescente. Disponível em: http://www.planalto.gov.br/ccivil_03/LEIS/L8069.htm. Acesso em: 22 de abr. 2019.

${ }^{5}$ Ver. BRASIL. Lei n. 8.069, de 13 de julho de 1990. Dispõe sobre o Estatuto da Criança e do Adolescente. Disponível em: http://www.planalto.gov.br/ccivil_03/LEIS/L8069.htm. Acesso em: 22 de abr. 2019.
} 
Criança e do Adolescente para, posteriormente, em cumprimento ao art. 50 desse mesmo estatuto, realizar uma prévia inscrição no Cadastro Nacional de Adoção.

A Lei Nacional de Adoção enunciou prazos para maior rapidez dos processos de adoção que, por meio de um cadastro nacional, de modo a facilitar o encontro de crianças e adolescentes aptas para adoção com pessoas habilitadas a adotarem, limitando, em sua redação original, a dois anos o tempo de permanência dos infantes em acolhimento familiar ou instituição familiar, prorrogáveis em caso de necessidade. Fixou, ainda, o prazo de seis meses para reavaliação da situação da criança e o adolescente.

Contudo, recentemente o Estatuto da Criança e do Adolescente sofreu modificações por meio da Lei no 13.509/17, com alteração dos dispositivos que regulamentavam os prazos para manutenção da criança e do adolescente em acolhimento institucional e revisão de sua situação.

Atualmente, com a Lei 13.509/17 houve uma redução do prazo de permanência da criança e do adolescente em programa de acolhimento institucional, o qual não será superior a 18 (dezoito) meses, salvo comprovada necessidade que atenda ao seu superior interesse, devidamente fundamentada pela autoridade judiciária. De igual modo, o prazo para reavaliação foi reduzido para 03 (três) meses, consoante art. 19, $\S 1^{\circ}$, do ECA.

Analisadas essas questões, vê-se que a primazia da adoção nacional é a regra, entretanto, superadas todas as tentativas de inserção da criança ou adolescente em uma família brasileira ou estrangeira residente no país, o Poder Público e o sistema judiciário recorrem ao instituto da adoção internacional, a fim de garantir aos infantes o direito à convivência familiar. Como prescrevem os artigos 31 e 51 do ECA, a adoção internacional é medida excepcional e somente será permitida entre países ratificantes da Convenção de Haia, principal norma jurídica relativa à Proteção das Crianças e à Cooperação em Matéria de Adoção Internacional.

Diante disso, assim como a Constituição Federal visa proteger os direitos dos infantojuvenis, com o advento do Estatuto da Criança e do Adolescente (Lei no 8.069/90), principal legislação normativa que visa defender os interesses desses infantes, a adoção passou a ser considerada como uma medida de proteção, fundamentada na dignidade da pessoa humana. 


\subsection{Estágio de convivência}

Antes de a adoção ser plenamente concretizada pelo Poder Judiciário, passase por uma fase denominada de estágio de convivência, período estipulado pelo magistrado a fim de ter certeza de que os adotantes estão realmente preparados para a adoção e se o adotando está satisfeito com o núcleo familiar que passará a integrar. Cumpre ressaltar que o estágio de convivência está normatizado no art. 46 do Estatuto da Criança e do adolescente. Vejamos:

Art. 46. A adoção será precedida de estágio de convivência com a criança ou adolescente, pelo prazo máximo de 90 (noventa) dias, observadas a idade da criança ou adolescente e as peculiaridades do caso.

$\S 1$ o O estágio de convivência poderá ser dispensado se o adotando já estiver sob a tutela ou guarda legal do adotante durante tempo suficiente para que seja possível avaliar a conveniência da constituição do vínculo. ${ }^{6}$

$(\ldots)$

Sob essa ótica, Venosa (2013, p. 301) esclarece:

Esse estágio tem por finalidade adaptar a convivência de adotando ao novo lar. O estágio é um período em que se consolida a vontade de adotar e de ser adotado. Nesse estágio, terão o juiz e seus auxiliares condições de avaliar a conveniência da adoção.

Em relação à adoção internacional, o estágio de convivência deverá ser cumprido no Brasil, preferencialmente na comarca de residência da criança ou adolescente, a fim de que seja mais fácil fiscalizar a relação entre o adotando e o adotante, devendo a autoridade judiciária competente fixar um prazo mínimo de 30 (trinta) dias e, no máximo, 45 (quarenta e cinco) dias, podendo tal prazo ser

\footnotetext{
${ }^{6}$ Ver. BRASIL. Lei n. 8.069, de 13 de julho de 1990. Dispõe sobre o Estatuto da Criança e do Adolescente. Disponível em: http://www.planalto.gov.br/ccivil_03/LEIS/L8069.htm. Acesso em: 22 de abr. 2019.
} 
prorrogável por até igual período, uma única vez, mediante decisão fundamentada, a teor do que dispõe o art. 46, em seu parágrafo $3^{\circ}$.

O parágrafo $4^{\circ}$ do dispositivo em estudo elenca a seguinte redação:

Art. 46, §4으 $\mathrm{O}$ estágio de convivência será acompanhado pela equipe interprofissional a serviço da Justiça da Infância e da juventude, preferencialmente com o apoio dos técnicos responsáveis pela execução da política de garantia do direito à convivência familiar, que apresentarão relatório minucioso acerca da conveniência do deferimento da medida. $(\ldots)$

Dessa maneira, a premissa maior do estágio de convivência visa estabelecer bases sólidas e harmônicas no relacionamento afetivo entre o adotando e o adotante, evitando, assim, um eventual insucesso na adoção.

\section{A VIOLAÇÃO AOS DIREITOS FUNDAMENTAIS DO ADOTANDO QUANDO DO ROMPIMENTO DO VÍNCULO EM VIRTUDE DA DESISTÊNCIA DOS ADOTANTES DURANTE O ESTÁGIO DE CONVIVÊNCIA.}

Ao iniciar um procedimento de adoção, tanto o adotando quanto os adotantes estão movidos pelo incessante desejo de constituir uma nova família, independentemente do vínculo biológico. Não restam dúvidas de que o estágio de convivência é um período extremamente importante para uma adoção bem sucedida, pois, nesse ínterim, o adotando está em fase de adaptação ao novo lar.

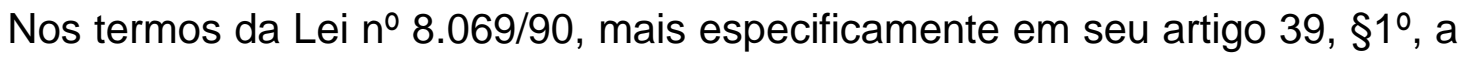
adoção é considerada medida excepcional e irrevogável. Devido a sua irrevogabilidade, deve-se levar em conta o melhor interesse da criança ou adolescente, dando-se a estes um estado de filho permanente, perene, e não suscetível às variações comportamentais e desejos dos adotantes.

Destarte, a jurisprudência posiciona-se da seguinte maneira:

ADOÇÃO. AÇÃO DE REVOGAÇÃO. IRREVOGABILIDADE. 1. É irrevogável a adoção consoante estabelece o art. 39, $\S 1^{\circ}$, do ECA, mesmo que tenha 
sido realizada antes do Estatuto da Criança e do Adolescente. 2. O art. 227, $\S 6^{\circ}$, da Constituição Federal de 1988 estabelece a igualdade jurídica de todos os filhos, qualquer que seja a natureza de filiação, incluindo também os havidos por adoção. 3. Os princípios postos na Carta Magna atingem todo o ordenamento jurídico e todas as relações nele inseridas, dando nova conformação legal ao próprio instituto da adoção. 4. Assim, não apenas a adoção, como o próprio reconhecimento de filho, é irrevogável (art. 1ํ da Lei no 8.560/92 e art. 1609 do CCB), sendo que a própria anulação do registro de nascimento, para ser admitida, deve ser sobejamente demonstrada como decorrente de vício do ato jurídico (coação, erro, dolo, simulação ou fraude). 5. Incorrendo qualquer vício na formalização da relação de paternidade de filiação, improcede a pretensão de desconstituir a adoção, pois tal vínculo é irrevogável. Recurso desprovido. (Apelação Cível № 70069445112, Sétima Câmara Cível, Tribunal de Justiça do RS, Relator: Sérgio Fernando de Vasconcelos Chaves, Julgado em 31/08/2016).

Com efeito, percebe-se que a adoção, após o trânsito em julgado da sentença que a proferiu, será medida irrevogável na qual o adotado perderá o vínculo com sua família de origem, conservando-se, entretanto, apenas, os impedimentos matrimoniais, conforme preceitua o art. 41, do ECA.

A adoção definitiva será sempre precedida pelo período de convivência. Contudo, é nesse mesmo período que começam a surgir os impasses da adoção, simplesmente porque os adotantes desistem da medida, sem motivos relevantes, o que acarreta na devolução da criança e/ou adolescente às instituições de acolhimento.

Em que pese à adoção possuir um caráter irrevogável, a devolução do adotando às instituições de acolhimento durante o estágio de convivência não é vedada, pelo fato de que não se sujeita à irrevogabilidade trazida pelo artigo $39, \S 1$, do Estatuto da Criança e do Adolescente.

Nesta senda, tem-se a análise jurisprudencial:

APELAÇÃO. AÇÃO CIVIL PÚBLICA. MENORES EM ESTÁGIO DE CONVIVÊNCIA COM CASAL ADOTANTE. DEVOLUÇÃO DAS CRIANÇAS. INDENIZAÇÃO POR DANO MORAL. O Estatuto da Criança e do Adolescente, em seu art. 46, prevê que a adoção será precedida de estágio de convivência, que, nada mais é do que um período de adaptação da criança com a nova família e dessa família com a criança. No caso, o estágio de convivência restou frustrado, seja pelo comportamento das crianças, entendido como inadequado pelos adotantes, ou mesmo por estes não estarem realmente preparados para receber novos membros na família. Contudo, não há vedação legal para que os futuros pais, ora recorridos, desistam da adoção quando estiverem apenas com a guarda dos menores. 
E a própria lei prevê a possibilidade de desistência, no decorrer do processo de adoção, ao criar a figura do estágio de convivência. RECURSO DESPROVIDO. (TJ-RS - AC: 70080332737 RS, Relator: Liselena Schifino Robles Ribeiro, Data de Julgamento: 28/02/2019, Oitava Câmara Cível, Data de Publicação: Diário da Justiça do dia 13/03/2019).

$\mathrm{Na}$ contramão desse raciocínio, apesar de a lei garantir essa faculdade aos adotantes, os infantes não podem ficar sujeitos a tal discricionariedade. Sendo assim, denota-se um conflito de interesses entre as partes envolvidas no processo, que consequentemente atinge sobremaneira os pretensos adotandos, desencadeando uma violação dos seus direitos fundamentais constitucionalmente garantidos.

Fato é que diante de todo esse dilema, desistir da adoção é deixar de propiciar aos infantes todos os direitos normatizados tanto pela Constituição Federal quanto pelo Estatuto da Criança e do Adolescente, conforme este estabelece em seu art. 3ํㅡ, caput, in verbis:

Art. $3^{\circ} \mathrm{A}$ criança e o adolescente gozam de todos os direitos fundamentais inerentes à pessoa humana, sem prejuízo da proteção integral de que trata esta Lei, assegurando-se-lhes, por lei ou por outros meios, todas as oportunidades e facilidades, a fim de lhes facultar o desenvolvimento físico, mental, moral, espiritual e social, em condições de liberdade e de dignidade.

Pela leitura do art. $3^{\circ}$, percebe-se a imprescindibilidade de assegurar às crianças e aos adolescentes os direitos fundamentais, que assim como foram trazidos pelo constituinte originário de 1988, o Estatuto da Criança e do Adolescente os incorporou em seus dispositivos legais, a fim de garantir-Ihes a devida proteção.

Como é de conhecimento geral, a criança e o adolescente que, por conta de sua condição peculiar de desenvolvimento, estão mais expostos às vulnerabilidades sociais se comparados aos adultos.

Partindo-se de um plano afetivo, é inegável que a partir do momento em que se desfaz o vínculo até então existente entre o adotando e o adotante, os efeitos negativos dessa ruptura surgirão. Logo, o infante passa a reviver todos os traumas já experimentados no rompimento de laços com a família natural.

De acordo com Silva e Pozzer (2014, p. 20): 


\begin{abstract}
Essa devolução ocorrida durante o estágio de convivência é sentida pela criança ou pelo adolescente como um segundo abandono, pois a criança foi rejeitada ou abandonada pelos seus pais biológicos e em um novo momento é novamente abandonada pelos pais adotivos, o que resulta em uma frustração imensa.
\end{abstract}

De modo idêntico, evidencia-se que muito embora os adotantes tenham a faculdade de desistir da adoção durante o estágio de convivência, deve-se levar em consideração principalmente no que tange ao princípio da prioridade absoluta, o qual tem sua previsão legal contida no art. 227, da Carta Magna, de que os direitos fundamentais da criança e do adolescente serão sobrepostos a quaisquer outras medidas.

A respeito do aludido princípio, esclarece acertadamente Nucci

$(2015$, p.08):

Todos têm direito à vida, à integridade física, à saúde, à segurança etc., mas os infantes e jovens precisam ser tratados em primeiríssimo lugar (seria em primeiro lugar, fosse apenas prioridade, porém, a absoluta prioridade é uma ênfase), em todos os aspectos. Precisam ser o foco principal do Poder Executivo na destinação de verbas para o amparo à família e ao menor em situação vulnerável; precisam das leis votadas com prioridade total, em seu benefício; precisam de processos céleres e juízes comprometidos.

Tamanha é a importância do princípio da prioridade absoluta, que o legislador infraconstitucional o consagrou no art. $4^{\circ}$, do Estatuto da Criança e do Adolescente, definindo como prioridade: a) primazia de receber proteção e socorro em quaisquer circunstâncias; b) precedência de atendimento nos serviços públicos ou de relevância pública; c) preferência na formulação e na execução das políticas sócias públicas; d) destinação privilegiada de recursos públicos nas áreas relacionadas com a proteção à infância e à juventude. 
Ressalta-se, contudo, que o rol trazido pelo art. 4ำ, não é taxativo, mas sim, exemplificativo, pois a aplicabilidade da prioridade absoluta pode se dar em inúmeras situações a depender do caso concreto.

Desfeito o vínculo do adotando com a futura família, este é devolvido à instituição de acolhimento. Muito embora as instituições de acolhimento atendam na maioria das vezes às necessidades básicas vitais das crianças e adolescentes que lá se encontram institucionalizados, "é evidente que outras deficiências estão presentes, principalmente as que envolvem o amparo afetivo". (ORIONTE; SOUSA, 2O05).

Evidentemente que a ruptura de vínculo dos pretensos adotantes com o adotando deixa de propiciá-lo outro importante direito fundamental garantido às crianças e aos adolescentes, que é a convivência familiar e comunitária, pois, por meio dela é conferido ao infante uma nova oportunidade de constituir um novo arranjo familiar, de desenvolver a sua personalidade e conhecer as suas potencialidades. Ora, a família é a base da estrutura do indivíduo.

O Estado Democrático de Direito como agente garantidor da dignidade humana, um dos fundamentos da República Federativa do Brasil, deve sempre buscar meios de resguardar os seus cidadãos de todas as vulnerabilidades presentes no contexto social.

De modo semelhante, ensina Costa (2008, p. 37):

(...) não mais se concebe o Estado de Direito como uma construção formal: é preciso que o Estado respeite a dignidade humana e os direitos fundamentais para que se possa ser considerado um Estado de Direito material. O Estado de Direito legitima-se pela subordinação à lei e, ao mesmo tempo, a determinados valores fundamentais, consubstanciados na dignidade humana.

Nesse viés, pode-se dizer que sem os direitos fundamentais, ou na eventualidade de sua supressão, "a pessoa humana não se realiza, não convive e, às vezes, nem mesmo sobrevive" (SILVA, 2008).

Diante dessa análise, resta demonstrado, ainda, que as atitudes dos futuros adotantes confrontam os preceitos do art. 15, do ECA, vejamos: " criança e o adolescente têm direito à liberdade, ao respeito e à dignidade como pessoas humanas 
em processo de desenvolvimento e como sujeitos de direitos civis, humanos e sociais garantidos na Constituição e nas leis".

Sendo assim, dada a sua condição peculiar, deve-se sempre atentar primeiramente aos direitos do adotando, tendo em vista que é inaceitável qualquer ato que os viole ou os contrarie.

As condutas irresponsáveis dos adotantes têm repercutido na seara jurídica, tanto que defende-se na doutrina e na jurisprudência brasileira a responsabilidade civil desses em diversos casos, com a condenação ao pagamento de indenizações aos adotantos.

Nesta senda, é o entendimento da jurisprudência do eg. Tribunal de Justiça de Minas Gerais:

EMENTA: APELAÇÃO CÍVEL. AÇÃO CIVIL PÚBLICA. MINISTÉRIO PÚBLICO. LEGITIMIDADE ATIVA. AD CAUSAM OCORRENTE. GUARDA PROVISÓRIA. DESISTÊNCIA DA ADOÇÃO DURANTE O ESTÁGIO DE CONVIVÊNCIA. NEGLIGÊNCIA E IMPRUDÊNCIAS DOS ADOTANTES CARACTERIZADA. DANO MORAL CONFIGURADO. DEVER DE INDENIZAR PRESENTE. VALOR DA INDENIZAÇÃO MANTIDO. RECURSO NÃO PROVIDO. 1. O art. 201, IX, da Lei no 8.069, de 1990 - Estatuto da Criança e do Adolescente confere legitimidade ativa extraordinária ao Ministério Público para ingressar em juízo na defesa dos interesses sociais e individuais indisponíveis afetos à criança e ao adolescente. 2. Assim, o Ministério Público tem legitimidade para propor ação civil pública, cujo objetivo é responsabilizar aqueles que supostamente teriam violado direito indisponível do adolescente. 3. Embora seja possível desistir da adoção durante o estágio de convivência, se ficar evidenciado que o insucesso da adoção está relacionado à negligência e à imprudência dos adotantes e que desta atitude resultou em comprovado dano moral para o adotando, este deve ser indenizado. 4. $O$ arbitramento da indenização pelo dano moral levará em conta as consequências da lesão, a condição socioeconômica do ofendido e a capacidade do devedor. Observados esses elementos, o arbitramento deve ser mantido. 5. Apelação Cível conhecida e não provida, mantida a sentença que acolheu em parte a pretensão inicial, rejeitada uma preliminar. (Grifei).

(...)

Ou seja, a dor, a angústia, o sentimento de abandono e o trauma vivenciado pelo substituído, bem como a correlação destes sentimentos com a desistência da adoção, torna forçosa a conclusão de que a lesão ao direito da personalidade e o nexo causal entre a ação perpetrada pelos recorrentes e o resultado lesivo estão presentes.

(...)

A convivência familiar é de fundamental importância para a formação do ser humano. E a adoção, embora seja uma medida de exceção à regra de preferência do convívio da família biológica, estabelece para os pais adotivos os mesmos direitos e obrigações próprios da relação biológica.

(...) 
O estágio de convivência não é, evidentemente, um lapso temporal voltado a um teste de viabilidade e conveniência da adoção para os pretensos adotantes, de modo que a desistência, sem uma justificativa lógica e razoável, pode sim resultar na responsabilização civil dos adotantes, inclusive gerar dever de indenizar eventual lesão a direito da personalidade do menor. (TJ-MG - AC: $10702140596124001 \mathrm{MG}$, Relator: Caetano Levi Lopes, Data de Julgamento: 27/03/2018, 2ª Câmara Cível, Data de Publicação: Diário da Justiça do dia 06/04/2018).

É claro que um valor indenizatório pago ao adotando, não vai suprir o afeto e o amor que deveria receber de uma família e muito menos apagar os traumas advindos do rompimento de vínculos, mas, de certo modo, os adotantes não podem sair ilesos ante a tal irresponsabilidade cometida em desfavor dos infantes.

\section{CONSIDERAÇÕES FINAIS}

Conforme foi visto, a legislação brasileira não veda a desistência da adoção, quando esta ainda se perpassa pelo estágio de convivência, ou seja, o Estado não vai agir coercitivamente para que os pretensos adotantes concluam o procedimento.

Por outro lado, diante desse contexto, depreende-se um conflito de interesses entre as partes envolvidas, em que há uma evidente violação aos direitos fundamentais do adotando. A Constituição Federal é enfática ao estabelecer que os direitos da criança e do adolescente serão sobrepostos aos demais, em razão da sua condição peculiar de ser em desenvolvimento. Sendo assim, a partir do momento em que se inicia o processo de adoção, o adotando passa a criar consigo expectativas de constituir uma nova família, e quando essas expectativas são frustradas em virtude das atitudes dos adotantes, deve prevalecer o direito do infante.

Diante de toda essa análise, a desconstrução de vínculos ocasionada pela devolução dos infantes durante o estágio de convivência, sem dúvida alguma, repercute negativamente ante aos interesses do adotando. O Estatuto da Criança e do Adolescente dispõe de todas as fases que compõem o procedimento da adoção, sendo os adotantes previamente informados da consecução de todos os atos do processo. Assim, muitas vezes, durante o estágio de convivência, os futuros pais decidem devolver o adotando como se fosse um "produto", alegando incompatibilidade afetiva entre eles, o que não representa medida justificável para tal 
devolução, uma vez que conflitos interpessoais estão intimamente ligados ao ser humano desde a sua criação.

Sendo assim, conforme foi exposto, evidenciou-se a existência da violação dos direitos fundamentais do adotando, o que inclusive já tem sido reconhecido pelos tribunais por meio de decisões em que os adotantes são condenados ao pagamento de indenização por danos morais.

\section{Referências}

BRASIL, Constituição (1988). Constituição Federal da República Federativa do Brasil. Brasília, 5 de outubro de 1988. Disponível em: http://www.planalto.gov.br/ ccivil_03/Constituicao/Constitui\%C3\%A7ao.htm. Acesso em: 22 de abr. de 2019.

BRASIL. Lei n. 8.069, de 13 de julho de 1990. Dispõe sobre o Estatuto da Criança e do Adolescente. Disponível em:

http://www.planalto.gov.br/ccivil_03/LEIS/L8069.htm. Acesso em: 22 de abr. 2019.

BRASIL. Tribunal de Justiça de Minas Gerais - Apelação Cível:

10702140596124001 MG, Relator: Caetano Levi Lopes Data de Julgamento:

27/03/2018, Data de Publicação: 06/04/2018. Disponível em

https://www.jusbrasil.com.br/jurisprudencia/busca?q=A\%C3\%A7\%C3\%A3o+de+dan os+morais+por+desist\%C3\%AAncia+de+adocao. Acesso em: 12 de jun. de 2019.

BRASIL. Tribunal de Justiça do Rio Grande do Sul - Apelação Cível: 70080332737 RS, Relator: LiselenaSchifino Robles Ribeiro, Data de Julgamento: 28/02/2019, Oitava Câmara Cível, Data de Publicação: Diário da Justiça do dia 13/03/2019. Disponível em:

https://www.jusbrasil.com.br/jurisprudencia/busca?q=IRREVOGABILIDADE+DA+AD O\%C3\%87\%C3\%83O. Acesso em: 12 de jun. de 2019.

BRASIL. Tribunal de Justiça do Rio Grande do Sul - Apelação Cível: 70069445112 RS, Relator: Sérgio Fernando de Vasconcellos Chaves, Data de Julgamento: 31/08/2016, Sétima Câmara Cível, Data de Publicação: Diário da Justiça do dia 06/09/2016. Disponível em: <https://tjrs.jusbrasil.com.br/jurisprudencia/381349561/apelacao-civel-ac-70069445112rs?ref=serp $>$. Acesso em: 12 de jun. de 2019.

CLARINDA, Katherine Scherer. A doutrina da proteção integral e os direitos fundamentais como ensejadores do reconhecimento da adoção por companheiros homoafetivos. Publicado em 09/2017. Disponível em:<https://jus.com.br/artigos/60561/a-doutrina-da-protecao-integral-e-os-direitos- 
fundamentais-como-ensejadores-do-reconhecimento-da-adocao-por-companheiroshomoafetivos > Acesso em: 22 de abril de 2019.

COSTA, Helena Regina Lobo da.A dignidade humana: teoria de prevenção geral positiva. São Paulo: Revista dos Tribunais, 2008.

DINIZ, Maria Helena. Curso de Direito Civil Brasileiro. Direito de Família. v. 5. São Paulo: Saraiva, 2010.

FELIPE, Luiza. A responsabilidade civil dos pretendentes à adoção nos casos de desistência da medida durante o estágio de convivência. Repositório institucional da UFSC. 02-12-2016. Disponível em:

https://repositorio.ufsc.br/bitstream/handle/123456789/172867/TCC\%20\%281\%29.p df?sequence=1\&isAllowed=y. Acesso em: 06 de jun. de 2019.

LÔBO, Paulo. Direito Civil. Famílias. 4. ed. São Paulo: Editora Saraiva, 2011.

NUCCI, Guilherme de Souza. Estatuto da Criança e do Adolescente Comentado: em busca da Constituição Federal das Crianças e dos Adolescentes. $2^{a}$ ed. Rio de Janeiro: Forense, 2015.

ORIONTE, Ivana; SOUSA, Sônia Margarida Gomes. O significado do abandono para crianças institucionalizadas. Psicologia em Revista, Belo Horizonte, n. 17. v 11, 2005. Disponível em: http://pepsic.bvsalud.org/pdf/per/v11n17/v11n17a03.pdf. Acesso em: 06 de jun. de 2019.

POZZER, Milene Ana dos Santos; SILVA, Maiara Patrícia. Responsabilidade civil pela devolução de crianças e adolescentes em estágio de convivência no processo de adoção. Revista Síntese, Direito de Família.

ROSENVALD, Nelson. Direito das Obrigações. 3. ed. Rio de Janeiro: Impetus, 2004.

SILVA, José Afonso da.Curso de direito constitucional positivo.31. Ed., São Paulo: Malheiros: 2008.

VENOSA, Sílvio de Salvo. Direito Civil: família. 13. ed. São Paulo: Atlas, 2013.

VERONESE, Josiane Rose Petry e PETRY, João Felipe Correa. Adoção internacional e Mercosul:aspectos jurídicos e sociais. Florianópolis: Fundação Boiteux, 2004. 
VERONESE, Josiane Rose Petry e SILVEIRA, Mayra. Estatuto da Criança e do Adolescente comentado. São Paulo: Conceito Editorial, 2011.

VERONESE, Josiane Rose Petry; COSTA, Marli Marlene Moraes da. Violência doméstica: quando a vítima é criança ou adolescente - uma leitura interdisciplinar. Florianópolis: OAB/SC, 2006. 